\title{
Spontaneous social tool use in chimpanzees (Pan troglodytes)
}

Running header: Social tool use

Manon K. Schweinfurth ${ }^{1 *}$, Sarah E. DeTroy ${ }^{2}$, Edwin J.C. van Leeuwen ${ }^{1,3}$, Josep Call ${ }^{1}$ \& Daniel B.M.

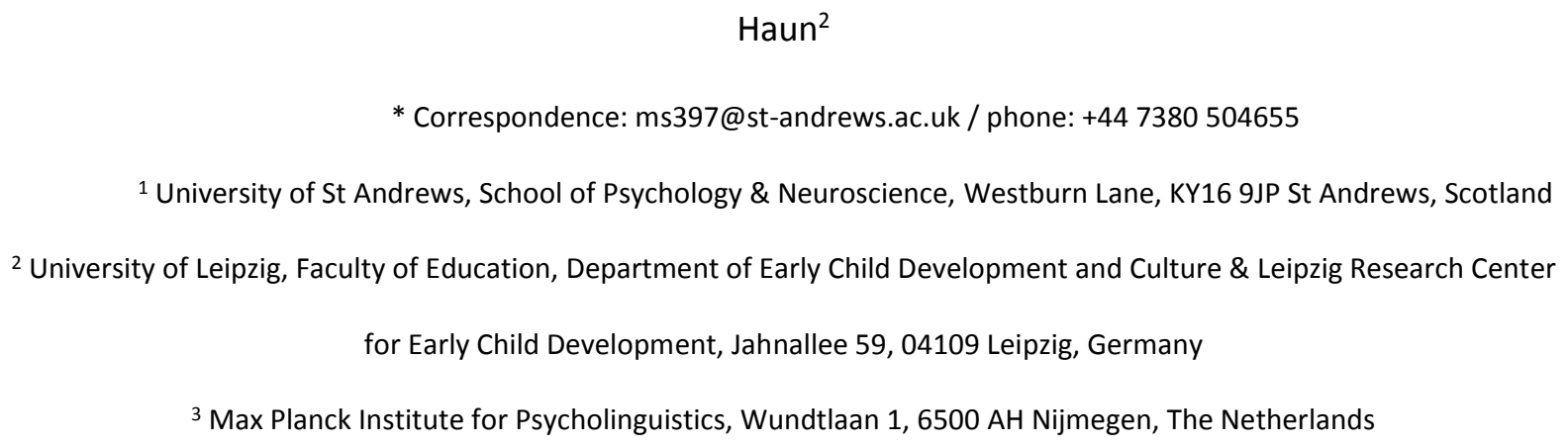

\section{Abstract}

While there is good evidence that social animals show elaborate cognitive skills to deal with others, there are few reports of animals physically using social agents and their respective responses as means to an end - social tool use. In this case study, we investigated spontaneous and repeated social tool use behaviour in chimpanzees (Pan troglodytes). We presented a group of chimpanzees with an apparatus, in which pushing two buttons would release juice from a distantly located fountain. Consequently, any one individual could only either push the buttons or drink from the fountain but never push and drink simultaneously. In this scenario, an adult male attempted to retrieve three other individuals and push them towards the buttons that, if pressed, released juice from the fountain. With this strategy, the social tool user increased his juice intake 10-fold. Interestingly, the strategy was stable over time, which was possibly enabled by playing with the social tools. With over 100 instances, we provide the biggest dataset on social tool use recorded among non-human animals so far. The repeated use of other individuals as social tools may represent a complex social skill linked to Machiavellian intelligence. 


\section{Introduction}

Many animals live, at least during some stage of their lives, in groups, ranging from loose and open aggregations to highly complex and closed societies (e.g., Krause \& Ruxton, 2002). Although group living is associated with several benefits including increased foraging success (Beauchamp, 1998), predator safety (Lehtonen \& Jaatinen, 2016), thermal protection (Gilbert et al., 2006) and energy savings (Herskin \& Steffensen, 1998), it does not come without costs. For instance, group-living animals face increased food (Janson, 1988) and mate competition (Wedell, Gage, \& Parker, 2002), risk of disease transmission (Côté \& Poulin, 1994) and infanticide (Crockett \& Janson, 2000). Complex social environments are characterised by a fine balance of competition and cooperation with multiple individuals interacting repeatedly over time in a variety of contexts, a setting that stands in stark contrast to the conditions operating in anonymous aggregations (Dunbar, 1998; see also Fischer, Farnworth, Sennhenn-Reulen, \& Hammerschmidt, 2017). It has been hypothesised that the particular challenges of complex social environments select for advanced socio-cognitive skills (Chance \& Mead, 1953; Humphrey, 1976; Jolly, 1966).

The Machiavellian Intelligence Hypothesis $(\mathrm{MIH})$, sometimes referred to as the "social complexity hypothesis", proposes that social competition within a social group is one of the main drivers for cognitive skills used to manipulate conspecifics to the benefit of the actor (Byrne \& Whiten, 1988). Although in some of their writings Whiten and Byrne (1988) mentioned both cooperation and competition as drivers of social intelligence, the adjective that they chose to describe their hypothesis (Machiavellian) paired with their empirical focus on tactical deception, largely explain why this hypothesis has become associated with social competition, and more specifically with the exploitation of conspecifics.

A far less subtle way to manipulate others than tactical deception, but still within the MIH's purview, involves using conspecifics as social tools. The meaning of social tool use, however, varies considerably across authors. Some researchers have defined "social tool" to denote cases where one animal 
interacts with a partner to influence a third party, such as in coalitionary support or agonistic buffering (Johnson \& Oswald, 2001). For instance, male Barbary macaques steal unweaned infants and use them as protection shields, e.g. agonistic buffers, to avoid aggressive encounters by other males (Deag \& Crook, 1971). Other authors have used the term social tool use to refer to the use of physical objects in social contexts, such as using a branch to display (Bard, 1990). We prefer to use the term social tool use in a narrower sense, to denote cases in which social agents physically coerce others to recruit their help (see also Gómez, 1990). This definition is comparable to physical tool use, which might be defined as "the exertion of control over a freely manipulable external object (the tool) with the goal of (1) altering the physical properties of another object, substance, surface or medium (the target, which may be the tool user or another organism) via a dynamic mechanical interaction, or (2) mediating the flow of information between the tool user and the environment or other organisms in the environment" (St Amant \& Horton, 2008).

Our narrower definition of social tool use fits the exploitative dimension of the MIH and it can take on several forms depending on the level of control between the user and its social tools (Völter, Rossano, \& Call, 2015, 2016). Level 1 describes situations in which the social tool is under full control of the user and is treated like a physical object. In level 2, the social tool user still has power over the social tool, but a response of the social tool is required, which cannot be fully controlled by the user. In level 3, the user relies on the self-initiated action by the social tool and thus control is further reduced. Finally, in level 4 the user requests help from the social tool and as such it is mediated by communicative acts (see also Gómez, 1990). While level 1 of social tool use is independent of a social tool's response, the other levels demand a coerced response of the social tool, which differs from physical tool use. Therefore, levels 2-4 are impossible to achieve with static physical tools.

Social tool use has not been often described in the literature and it is far less common than physical tool use, given the frequent reports of the latter (e.g., Shumaker, Walkup, \& Beck, 2011). Still, there are some reports of social tool use among non-human primates. Sumatran orang-utan mothers (Pongo abelii) used their immature offspring to retrieve food by actively pushing them towards out-of-reach 
food, which they eventually steal from their infants in an experimental study (Völter et al., 2015). In the same experimental setting chimpanzee (Pan troglodytes) and bonobo (Pan paniscus) mothers allowed their offspring to eat the retrieved food without any harassment or stealing attempts (Völter et al., 2016). A similar case of social tool use was reported in free-ranging Japanese macaques (Macaca fuscata): three females used their infants to climb into a pipe to collect apple slices, which were afterwards solely eaten by the mothers (Tokida, Tanaka, Takefushi, \& Hagiwara, 1994).

Because the benefits of exploiting others lead to success by gaining resources or mates, they ultimately translate into increased fitness. Therefore, such skills are expected to evolve readily (Gavrilets \& Vose, 2006). In addition, if one individual uses a strategy to exploit others, they are expected to develop counter strategies, leading to constant feedback loops as has been detected for some cases of tactical deception (e.g., Coussi-Korbel \& Fragaszy, 1995; Hirata \& Matsuzawa, 2001; Menzel, 1974; see also Byrne \& Whiten, 1992). One strategy, which could enable the repeated exploitation of others, is to provide them with some form of benefit, such as grooming or social play, which in turn may reduce counter strategies. Eventually, this spiralling effect may lead to more and more complex skills both during ontogeny and phylogeny (cf. Fisher, 1915). Finally, this process leads to superior socio-cognitive skills in species living in complex social environments (as defined earlier) compared to species living in simpler social environments.

In the present study, we report a spontaneously occurring example of social tool use in chimpanzees. By analysing these spontaneous occurrences of social tool use in chimpanzees, we aimed to shed new light on an aspect of the $\mathrm{MIH}$ that has received relatively little attention. Although cases of social tooluse in non-human animals are witnessed occasionally (Melis, pers. comm.; Hopkins, pers. comm.), they are rarely studied systematically. We think that a careful quantification of those data as well as a precise description of the conditions in which they occurred are essential to advancing our knowledge in this area. Thus, we here document the manipulative actions of an adult male chimpanzee towards three group members. In addition, we investigated the success and development of such manipulative acts over time. Furthermore, we investigated whether the social tool user showed a preference for 
using particular individuals over others and whether the "social tools" differed in their response to the manipulations. Finally, we recorded social play during and shortly after social tool use to test for a possible association between exploiting others and providing them with benefits. We recorded social play because (i) other candidate behaviours, i.e. grooming, were rarely seen in this context and (ii) social play sometimes transformed into social tool use.

\section{Methods}

\section{Subjects and study site}

The study was conducted in 2017 at the Chimfunshi Wildlife Orphanage Trust, which is a chimpanzee sanctuary located in Northwestern Zambia. At this time, the sanctuary hosted 119 chimpanzees that lived in several groups comprised of wild-born and sanctuary-born individuals. They were housed in enclosures of sizes up to 77 hectares, surrounded by electric fences. During feeding times ( 2 hours a day), chimpanzees were called into indoor handling facilities with several rooms and were provided with nshima balls (maze flour cooked with water) and local seasonal fruits and vegetables. Outside of the feeding time, the individuals were able to freely range in their enclosures.

This study made use of a spontaneously occurring behaviour by one individual of 'group 4', with which we conducted the fruit juice experiment (see below). This group consisted of 11 individuals, housed in a 25-hectare outdoor enclosure (SI tab. 1 for more information on the group members). The social tool user was a mid-ranking adult male, named Bobby. He was born in the wild, approximately in 1993. In 2000, he was rescued from being a tourist attraction in a restaurant in the Central African Republic, where he daily interacted with many tourists. When he arrived in Chimfunshi he was in good physical condition.

\section{Apparatus}

The setup consisted of a drinking fountain, two retractable buttons that were installed in the enclosure and a tank containing juice placed on top of the feeding house outside of the enclosure (fig. 1). The 
buttons were connected underground via hosepipes to the fountain. The experimenters could manipulate the buttons from outside the enclosure. The buttons were only present during the testing sessions.

132

\section{Procedure}

Before each session, the experimenter flushed some juice through the fountain to signal the start of the session. Thereafter, the chimpanzees needed to push the two buttons simultaneously to deliver juice to the distant fountain, from which others could drink. The setup created a dilemma because the pushers could not directly drink from the fountain because the flow of juice stopped as soon as the buttons were released. In prior experiments, the chimpanzees had already learned to push a single button that released juice at a juice fountain (van Leeuwen et al., in prep.), however they had never been confronted with a condition in which two buttons needed to be pushed simultaneously to release juice.

\section{Data coding and analyses}

We conducted 49 sessions lasting between 1 and 2 hours each. We videotaped all sessions with camcorders (JVC-Everio) obtaining a total of 90 hours of video footage. During the sessions, the experimenters, who were present at all times, noted down the social tool use events. The start of each sequence was defined by the first occurrence of any behaviour that was involved in increasing the chance for receiving juice through the social tool user. Each sequence was stopped at 5 minutes after the last social tool use attempt. Afterwards these sequences were extracted using the VLC media player. The respective sequences were coded using Solomon Coder (version 17.03.22). A second coder independently scored $20 \%$ of the videos to assess inter-observer reliability. We chose the videos randomly, but we ensured that videos from the beginning and end of the testing period were included in the subset. We tested for reliability by calculating the Cohen's Kappa for count data. Scores given to the social tool user and the social tools by the two observers were highly correlated ( $F$-test: $F_{63}=12.3$, $p<0.0001$ ) with a Cohen's Kappa of 0.85 and a 95\% confidence interval of 0.14 . 
We scored the behaviour of the social tool user and the responses of the social tools. Table 1 provides

155 a detailed description of the behaviours (see also the video included in the supplementary material).

156 Additionally, we scored the social tool user's success and his control over the social tools.

157 Behaviour of the social tool user: First, we identified and described the behaviour by the social tool

158

159

160

161

162 user (Bobby [24 years old at the time of data collection]) towards his three social tools (Jack [9 years old], Jewel [4 years old] and Kenny [6 years old]). Because Jack was involved in only one case, we excluded him from further analyses. We recorded the durations of all behaviours, which highly correlated with its frequency (see SI) and hence we report statistical analysis on the count data. The first attempt to use one of the social tools was recorded in session 12 . We analysed whether the levels of social tool use differed over time using zero-inflated regression models for count data, which account for behavioural data that include zeros. We included the respective social tool use behaviours as response variables (one model for each behaviour) and included the session number and social tool identity as explanatory variables. We assumed a negative binomial distribution and only report results from models with a non-significant theta value, indicating an appropriate fit of the model (Zuur, leno, Walker, Saveliev, \& Smith, 2009).

We also recorded any playful behaviour between the user and his social tools during the time from the first element of social tool use until 5 minutes after the last element. Rough and tumble play was defined according to Nishida, Kano, Goodall, McGrew, \& Nakamura, 1999 as a physical social play that includes: tag, wrestle, push, pull, bite, drag, stamp, slap, thrust and leap. Importantly, all these behaviours occurred in proximity to the experimental device but were not directed to it, as for instance pushing the social tool into the direction of the buttons. We tested whether the two social tools differed in their duration of playing with the social tool user by using a Mann-Whitney-U-test.

Success of the social tool user: We determined the success of the user's strategy by calculating the increase of juice donations by comparing the coerced and uncoerced donations by the two social tools, Kenny and Jewel. We defined a coerced pushing event as Bobby pushing or herding the social tool 
towards the buttons and all following pressing events without the social tool distancing itself from buttons by more than 3 meters. All other pushing events were defined as uncoerced, in which the social tools approached the buttons alone and had not been harassed by Bobby immediately before. In addition, we report the overall drinking rate, standardised by time of observations, before and after Bobby used social tools.

Control over social tool: Social tools could either press the buttons or try to escape by running away or avoiding the buttons after a social tool use attempt. Hence, we recorded in how many trials the social tool user responded to an escape by either retrieving or pushing the social tool back into the direction of the buttons. We consider a behaviour to be a response by the actor to an escape attempt, if the user responded within 60 seconds of the beginning of the escape attempt.

Response of social tools: We recorded the response of the social tools, namely whether they pressed the buttons and the latency until the behaviour was executed. We tested whether the two social tools differed in their response by using a Generalised Linear Mixed Model with Poisson error distribution and log link function. We included how often the social tools pressed the buttons as a response variable, the social tool identity (Jewel or Kenny) as an explanatory variable and the session number as random effect. The model did not show overdispersion, indicating an appropriate fit (Crawley, 2007). Furthermore, we tested whether the social tools differed in their response when being coerced to help by performing a Generalised Linear Mixed Model with a binomial error distribution and logit link function. We included the social tools' response (escape or press the buttons) as a binomial response variable into the model with two random effects, which were the social tool identity and the session number. Finally, we tested whether the time to press the button by the social tools is dependent on the user's gestures by calculating a survival analysis. We included "the time interval between Bobby pushing the social tool until the social tool pressed the buttons" as response variable. We included the information of whether Bobby reached out during the time interval. To correct for the different social tools, we included them as a random factor. 
All statistical analyses and graphs were performed in R (version 3.4.2, http://www.r-project.org; with R studio and packages 'Ime4', 'ggplot2', 'cowplot', 'pscl, 'Hmisc', 'irr', and 'survival'). Because the data were not normally distributed, we report non-parametric tests throughout the manuscript (see SI).

\section{Ethical statement}

Our study was approved by the ethics committee of the host sanctuary (the Chimfunshi Research Advisory Board). All chimpanzees participated voluntarily in the project. The chimpanzees were never food or water deprived, nor were any chimpanzees separated from their group at any time. In addition, the animals were constantly monitored during all sessions and if any deviant behaviour or unexpected physical reaction had occurred, the experiments could have been stopped immediately, which was not the case. Finally, we adhered to the legal requirements of the Zambia Wildlife Authority (ZAWA) and the Ethical Treatment of Nonhuman Primates guidelines by the International Primatological Society's Principles.

\section{Results}

Behaviour and success of the social tool user

We recorded 146 instances of the tool user (Bobby) actively pushing one of the three social tools into the direction of the buttons that could be used to induce juice flow (Kenny= 118 , Jewel= 26, Jack= 2). In 78 cases, Bobby retrieved Kenny (73) and Jewel (5) from a distance of more than 3 meters (sometimes from more than 10 meters) before directing them to the buttons. While sitting in front of the fountain, Bobby held his hand out to Kenny and Jewel in 19 and 11 times, respectively. Bobby typically blew raspberries while he displayed these behaviours. In all of the cases, retrieving and pushing the social tools occurred before reaching out or blowing raspberries. The juveniles provided juice to Bobby in 115 cases (Kenny= 70, Jewel= 45), which includes cases where the social tools pressed several times in response to Bobby's actions. 
Bobby did not change his behaviour over time after he had started using the juveniles as tools (herding: GLM: $\beta=-0.02 \pm 0.03, p=0.50$; pushing: GLM: $\beta=-0.05 \pm 0.03, p=0.15$; reaching out: GLM: $\beta=0.01 \pm$ 0.03, $p=0.70$; blowing raspberries: GLM: $\beta=0.01 \pm 0.03, p=0.83$, fig. 2 a-d). Overall, he herded (GLM: $\beta=2.71 \pm 1.17, p=0.020$, fig. 2 a) and pushed (GLM: $\beta=1.10 \pm 0.44, p=0.011$, fig. 2 b) Kenny more often than Jewel. In contrast, reaching out was directed equally often at both juveniles (GLM: $\beta=-0.38 \pm 0.41$, $p=0.36$, fig. 2 c). Bobby's actions were associated with play behaviour. Overall, Bobby and Kenny spent more time playing with each other than Jewel and Bobby (Mann-Whitney U test: W=274.50, $p=0.002$, fig. S1).

Kenny pressed the buttons 538 times over all sessions irrespectively for whom and Jewel pressed the buttons 1154 times. By coercing the juveniles, Bobby's success in obtaining juice increased substantially (Kenny provided juice in 83 cases and Jewel in 54). Furthermore, after he started using the juveniles, his drinking bouts per hour increased from 0.53 to 5.01 (fig. S2). Bobby got access to juice not only by his social tools. However, he increased his juice intake by $48 \%$ through using social tools. If the juveniles tried to escape, Bobby retrieved or pushed them back in $46 \%$ of the cases within a median response time of 10.2 seconds $(I Q R=20.3)$.

\section{Response by the social tools}

In general, Kenny pressed the buttons for Bobby more often than Jewel after being harassed by Bobby (GLMM: $\beta=0.44 \pm 0.19, p=0.021$, fig. S3). We then tested whether one tool was more likely to respond with pressing the buttons than the other and found a non-significant trend that Jewel tended to respond more by pressing the buttons for Bobby than Kenny (GLMM: $\beta=0.68 \pm 0.38, p=0.075$, fig. 3). The social tools' latency to press the buttons was not influenced by Bobby reaching out to the social tools (Proportional Hazards Regression Model: $\beta=0.10 \pm 0.23, p=0.66$ ). 
We observed an adult male chimpanzee (Bobby) repeatedly using two juveniles (Kenny \& Jewel) as

252

253

254

255 social tools to obtain juice (a third, 8-year-old juvenile was used only in one sequence). Bobby displayed several behaviours aimed at enticing the juveniles to press a pair of buttons that activated a juice fountain located 3 meters away from them. His behaviour varied in the level of control over the juveniles. First, he actively recruited them by rolling or dragging them towards the buttons. In those situations, the juveniles seldom had the chance to escape and were under Bobby's almost full control and in constant contact. Next, Bobby pushed the juveniles in the direction of the buttons. Because the buttons and the fountain were three meters apart, he had to release them in order to drink from the fountain. Hence, his control was limited, and the juveniles could decide whether to press the buttons or to escape. In the case of escaping, however, the social tool user successfully retrieved them in almost half of the cases, suggesting some form of control. Social tool use was accompanied by blowing raspberries and reaching out. The latter was clearly directed towards the juveniles and might have served as begging, although it did not lead to a faster response by them. Blowing raspberries was not apparently directed at the juveniles given that it was sometimes emitted when Bobby was alone, and thus might indicate a general state of arousal.

The benefit for the adult male in using the juveniles was a marked increase in juice intake that persisted over time. In contrast, juveniles received no juice in return for their efforts. In fact, Bobby systematically pushed them away from the fountain when they approached it. Moreover, we observed no reciprocal turn-taking in pressing the buttons by Bobby and any of the juveniles because he never successfully pushed both buttons and released juice from the fountain in this study. This finding is consistent with other cases of social tool use in which a large power differential between motheroffspring dyads or even unrelated pairs of individuals determines the control exerted by the dominant over the subordinate's behaviour and the biased distribution of resources (Chalmeau, 1994; Tokida et al., 1994; Völter et al., 2015). However, social tool use does not always require a power asymmetry based on a large discrepancy in terms of age, status and body size. Chalmeau, Lardeux and Brandibas 
(1997) reported social tool use between two orang-utans of approximately the same age. In addition

to work on primates, Tebbich, Taborsky and Winkler (1996) observed that dominant keas coerced subordinate individuals to sit on a seesaw to open a container with food for the user. This study is particularly interesting because it shows that social tool use also occurs in non-primates.

One puzzling result is that since the juveniles received no tangible benefit, one would have predicted an overall decrease over time. If social tools started to avoid the user, there should be a decrease in social tool use. This is precisely what Chalmeau (1994) observed in a dyad of chimpanzees, where the harassed subordinate female escaped in most of the cases, which led the user to use her less often over time. In our case, we found no evidence that the user had to retrieve the social tools more often by the end of the study, which might indicate that social tools started to avoid Bobby. The juveniles' participation is even more puzzling when one considers that the control exerted by Bobby also had its limits. We recorded two aggressive instances after the social tools shortly screamed while the user tried to retrieve them after an escape attempt. In both cases, unrelated adult males rushed over and the tool user was readily displaced. In fact, Völter and colleagues (2016) argued that social tool use between mother-offspring dyads was more prevalent among orang-utans compared to chimpanzees and bonobos, because chimpanzee and bonobo infants protested more intensively, thus bringing attention to this situation by other group members. The two cases that we observed, lend some support to this interpretation.

One way to characterize social tool use is in terms of exploitation, i.e., one partner benefits and the other does not, despite the social tool's 'costly' participation. However, such characterisation may overlook that the juveniles may have actually obtained some benefit, such as play, which could explain why they continued to allow themselves to be manipulated. This is of special interest considering the limits to the manipulation that Bobby could exert as indicated by the two aggressive incidents that we observed. To address this issue, we turn our attention to two questions: why Bobby targeted the juveniles in the group and why the juveniles continued to participate in these episodes. 
One possibility is that Bobby focused on the juveniles instead of other group members because they were the lowest ranking members of the group, or perhaps the only ones that Bobby clearly outranked in the group. In other words, Bobby may have tried to maximise the power differential between him and his social tools, a factor that is associated with social tool use in most studies. Because the action of pressing the buttons cannot be fully controlled by the user, older group members might not be as easily coerced as younger individuals and might put up a serious fight when being harassed. Another possibility is that Bobby focused on the juveniles because their age made them more suitable for physical and motivational manipulation. Although this explanation partly overlaps with the previous one, it does not do so entirely. Compared to adult individuals, juveniles are more easily pushed and dragged around, and they may offer less resistance to such invasive behaviour.

From a motivationally point of view, the juveniles may have tolerated the large asymmetry in juice intake better than adults. In other words, adults may have been more likely than juveniles to expect a share of the resources. Male juveniles' interest in associating with adult males (Pusey, 1990) and the prevalence of play among immature individuals (Burghardt, 2005) may have further contributed to making the juveniles particularly effective social tools. Although both juveniles pressed the buttons regularly, Bobby preferred to use the older juvenile (Kenny) from whom he obtained more juice. This preference cannot be explained by a greater success rate when Bobby tried to use Kenny because the less used individual (Jewel) tended to respond more with pressing the buttons than escaping. In other words, 6-year-old Kenny seemed more compliant than 4-year-old Jewel. It is conceivable that a greater motivation to associate with adult males may explain the more frequent interactions between them and, consequently, the more numerous attempts to use Kenny. Furthermore, Kenny and Bobby also played more with each other during or shortly after social tool use. During those play episodes, both Bobby and his social tool displayed a play face. Play is a pleasurable and rewarding behaviour (Trezza, Baarendse, \& Vanderschuren, 2010). The balance between playing and using the social tools might explain why the juveniles did not avoid Bobby over time. However, this hypothesis needs to be tested in future studies. Moreover, whether play was a by-product of the increased association between the 
juveniles and the adult male over time or a tactic deployed by Bobby to secure Kenny's collaboration

328 is also an open question. If the latter were the case, this instrumental use of play would be comparable

329 to the cases of grooming directed to mothers to gain access to their infants that have been labelled as 'distraction' in the tactical deception literature (Byrne \& Whiten, 1988, 1992; Mitchell, 1988).

331 Future studies on the development of social tool use could provide important insights into the causal 332 understanding of the social tool user and its actions. In theory, three underlying mechanisms are possible (cf. Seed \& Byrne, 2010). First, social tool users could learn from others how to use social tools effectively. Second, social tool users might learn via trial-and-error that the manipulation of others lead to selfish benefits. Finally, social tool users might causally understand that a social tool is needed to reach a certain goal. We think that in our case social learning is the least likely possibility because

337 Bobby was the only individual showing this behaviour during the time of data collection. Whether he

338 found social tool use as a solution to the dilemma by insight or trial and error is difficult to discern 339 without careful experimental manipulations of the context but it could be addressed in further studies.

340 While our case study consists of a sample size of only one social tool user and his three social tools, we

341 obtained the largest dataset to date, as far as we are aware, in terms of occurrences of this behaviour.

342 However, case studies like ours make generalisations difficult. For instance, the adult male was rescued 343 from mistreatment by humans, which may have resulted in an inability to interact appropriately with 344 conspecifics. However, the data available in the literature, particularly the studies focusing on mother345 offspring pairs in apes and macaques, weaken this possibility considerably. Alternatively, social tool346 use might be restricted to fixed groups with no possibility to disperse, as in a sanctuary or laboratory 347 settings. Data from field studies are needed to answer this question.

348 In sum, we have shown that a chimpanzee spontaneously started using group members as social tools 349 under semi-natural conditions. The tool user actively retrieved his social tools and pushed them to 350 buttons that produced juice when pressed. Because pressing the buttons for his own benefit was not 351 possible, Bobby was dependent on others to press the buttons for him. Although the tool user did not 
352 have full control over the social tools, he was able to increase his juice intake almost 10-fold. Playing

353 with the social tools might have stabilised Bobby's strategy over time. The balance between using

354 others for the actor's own benefit and preventing the social tools from avoiding the actor might be an

355 example of Machiavellian intelligence. Future studies are needed to understand how widespread social

356 tool use is in chimpanzees and other species, and how the social and ecological settings affect its

357 occurrence. Such data will enable the systematic investigation of its origins and psychological

358 underpinnings.

\section{Acknowledgements}

361 We would like to thank the Chimfunshi Wildlife Orphanage Trust and all staff members for their ongoing support of our research. We are also grateful to Sebastian Schütte for developing and setting up the fruit juice device and Bianca Dietrich for her help in collecting part of the data. This research was supported by the European Research Council (Synergy grant 609819 SOMICS to JC). MKS was supported by the SNF-grant P2BEP3 175269. 


\section{Literature}

Beauchamp, G. (1998). The effect of group size on mean food intake rate in birds. Biological Reviews, 73(4), 449-472. https://doi.org/10.1111/j.1469-185X.1998.tb00179.x

Burghardt, G. M. (2005). The genesis of animal play: testing the limits. Cambridge: MIT Press.

Byrne, R. W., \& Whiten, A. (1988). Machiavellian intelligence. Oxford: Oxford University Press.

Byrne, R. W., \& Whiten, A. (1992). Cognitive evolution in primates: evidence from tactical deception. Man, 27(3), 609-627. https://doi.org/10.2307/2803931

Chalmeau, R. (1994). Do chimpanzees cooperate in a learning task? Primates, 35(3), 385-392.

Chalmeau, R., Lardeux, K., \& Brandibas, P. (1997). Cooperative problem solving by orangutans (Pongo pygmaeus). International Journal of Primatology, 18(1), 23-32.

Chance, M. R. A., \& Mead, A. P. (1953). Social behaviour and primate evolution. Symposia of the Society for Experimental Biology, 7, 395-439.

Côté, I. M., \& Poulin, R. (1994). Parasitism and group size in social animals: a meta-analysis. Behavioral Ecology, 6(2), 159-165. https://doi.org/10.1093/beheco/6.2.159

Coussi-Korbel, S., \& Fragaszy, D. M. (1995). On the relation between social dynamics and social learning. Animal Behaviour, 50, 1441-1453.

Crawley, M. J. (2007). The R book. John Wiley \& Sons Ltd, The Atrium, Southern Gate, Chichester. https://doi.org/10.1017/СВ09781107415324.004

Crockett, C. M., \& Janson, C. H. (2000). Infanticide in red howlers: female group size, group composition and a possible link to folivory. In C. P. van Schaik \& C. H. Janson (Eds.), Infanticide by males and its implications (pp. 75-98). Cambridge: Cambridge University Press.

Deag, J. M., \& Crook, J. H. (1971). Social behaviour and "agonistic buffering" in the wild Barbary macaque Macaca sylvana L. Folia Primatologica, 15, 183-200.

Dunbar, R. (1998). The social brain hypothesis. Evolutionary Anthropology, 6, 178-190. https://doi.org/10.1002/(SICI)1520-6505(1998)6:5<178::AID-EVAN5>3.3.CO;2-P 
Fischer, J., Farnworth, M. S., Sennhenn-Reulen, H., \& Hammerschmidt, K. (2017). Quantifying social complexity. Animal Behaviour, 130, 57-66. https://doi.org/10.1016/j.anbehav.2017.06.003

Fisher, R. A. (1915). The evolution of sexual preference. The Eugenics Review, 7(3), 184-192.

Gavrilets, S., \& Vose, A. (2006). The dynamics of Machiavellian intelligence. Proceedings of the National Academy of Sciences, 103(45), 16823-16828. https://doi.org/10.1073/pnas.0601428103

Gilbert, C., Robertson, G., Le Maho, Y., Naito, Y., \& Ancel, A. (2006). Huddling behavior in emperor penguins: dynamics of huddling. Physiology and Behavior, 88, 479-488. https://doi.org/10.1016/j.physbeh.2006.04.024

Gómez, J. C. (1990). The emergence of intentional communication as a problem-solving strategy in the gorilla. In S. T. Parker \& K. R. Gibson (Eds.), "Language" and intelligence in monkeys and apes - comparative developmental perspectives (pp. 333-355). Cambridge: Cambridge University Press.

Herskin, J., \& Steffensen, J. F. (1998). Energy savings in sea bass swimming in a school: measurements of tail beat frequency and oxygen consumption at different swimming speeds. Journal of Fish Biology, 53, 366-376. https://doi.org/10.1111/j.1095-8649.1998.tb00986.x

Hirata, S., \& Matsuzawa, T. (2001). Tactics to obtain a hidden food item in chimpanzee pairs (Pan troglodytes). Animal Cognition, 4(3-4), 285-295. https://doi.org/10.1007/s100710100096

Humphrey, N. K. (1976). The social function of the intellect. In P. P. G. Bateson \& R. A. Hinde (Eds.), Growing Points in Ethology (pp. 303-317). Cambridge: Cambridge University Press.

Janson, C. H. (1988). Food competition in brown capuchin monkeys (Cebus apella): quantitative effects of group size and tree productivity. Behaviour, 105(1/2), 53-76.

Johnson, C. M. ., \& Oswald, T. M. (2001). Distributed cognition in apes. Proceedings of the Annual Meeting of the Cognitive Science Society, 23(23), 453-458.

Jolly, A. (1966). Lemur social behavior and primate intelligence. Science, 153(3735), 501-506. 
Kim A. Bard. (1990). "Social tool use" by free-ranging orangutans: a Piagetian and developmental perspective on the manipulation of an animate object. In S. T. Parker \& K. R. Gibson (Eds.), "Language" and intelligence in monkeys and apes: comparative developmental perspectives (pp. 356-379). Cambridge: Cambridge University Press.

Krause, J., \& Ruxton, G. D. (2002). Living in groups. Oxford Series in Ecology and Evolution. https://doi.org/10.1093/sysbio/sys022

van Leeuwen, E. J. C., DeTroy, S. E., Kaufhold, S., Dubois, C., Call, J., \& Haun, D. B. M. (in prep.). Group identity shapes prosocial decision-making in semi-wild chimpanzees

Lehtonen, J., \& Jaatinen, K. (2016). Safety in numbers: the dilution effect and other drivers of group life in the face of danger. Behavioral Ecology and Sociobiology, 70(4), 449-458. https://doi.org/10.1007/s00265-016-2075-5

Menzel, E. W. (1974). A group of young chimpanzees in a one-acre field. In A. Schrier \& F. Stollnitz (Eds.), Behavior of nonhuman primates: modern research trends (pp. 83-153). New York: Academic Press.

Mitchell, R. W. (1988). Ontogeny, biography, and evidence for tactical deception. Behavioural and Brain Sciences, 11, 259-260. https://doi.org/10.1017/S0140525X00049682

Nishida, T., Kano, T., Goodall, J., McGrew, W. C., \& Nakamura, M. (1999). Ethogram and ethnography of Mahale chimpanzees. Anthropological Science, 107(2), 141-188. https://doi.org/10.1537/ase.107.141

Pusey, A. E. (1990). Behavioural changes at adolescence in chimpanzees. Behaviour, 115, 203-246. https://doi.org/10.1007/s

Seed, A., \& Byrne, R. (2010). Animal tool-use. Current Biology, 20(23), 1032-1039. https://doi.org/10.1016/j.cub.2010.09.042

Shumaker, R. W., Walkup, K. R., \& Beck, B. B. (Eds.). (2011). Animal tool behavior: the use and manufacture of tools by animals. Baltimore: The Johns Hopkins University Press. 
St Amant, R., \& Horton, T. E. (2008). Revisiting the definition of animal tool use. Animal Behaviour, 75(4), 1199-1208. https://doi.org/10.1016/j.anbehav.2007.09.028

Tebbich, S., Taborsky, M., \& Winkler, H. (1996). Social manipulation causes cooperation in keas. Animal Behaviour, 52(1), 1-10.

Tokida, E., Tanaka, I., Takefushi, H., \& Hagiwara, T. (1994). Tool-using in Japanese macaques: use of stones to obtain fruit from a pipe. Animal Behaviour, 47(5), 1023-1030.

Trezza, V., Baarendse, P. J. J., \& Vanderschuren, L. J. M. J. (2010). The pleasures of play: pharmacological insights into social reward mechanisms. Trends in Pharmacological Sciences, 31(10), 463-469. https://doi.org/10.1016/j.tips.2010.06.008

Völter, C. J., Rossano, F., \& Call, J. (2015). From exploitation to cooperation: social tool use in orangutan mother-offspring dyads. Animal Behaviour, 100, 126-134. https://doi.org/10.1016/j.anbehav.2014.11.025

Völter, C. J., Rossano, F., \& Call, J. (2016). Social manipulation in nonhuman primates: cognitive and motivational determinants. Neuroscience and Biobehavioral Reviews, in press. https://doi.org/10.1016/j.neubiorev.2016.09.008

Wedell, N., Gage, M. J. G., \& Parker, G. A. (2002). Sperm competition, male prudence and sperm limited females. Trends in Ecology and Evolution, 17(7), doli. https://doi.org/10.1016/S0169$5347(02) 02533-8$

Zuur, A. F., leno, E. N., Walker, N. J., Saveliev, A. A., \& Smith, G. M. (2009). Zero-truncated and zeroinflated models for count data. In Mixed effects models and extensions in ecology with $R$ (pp. 261-293). New York: Springer. 


\begin{tabular}{|c|c|c|}
\hline Social tool use behaviour & Actor: social tool user & Social tool use levels \\
\hline retrieve [78] & $\begin{array}{l}\text { - herding by closely walking behind the } \\
\text { tool and gently touching it } \\
\text { dragging the tool to the experimental } \\
\text { device } \\
\text { rolling the tool towards the experimental } \\
\text { device }\end{array}$ & $\begin{array}{l}\text { level 1: complete } \\
\text { physical control }\end{array}$ \\
\hline push [146] & $\begin{array}{l}\text { - pushing the tool forcefully into the } \\
\text { direction of the buttons and releasing it }\end{array}$ & $\begin{array}{l}\text { level 2: partial physical } \\
\text { control }\end{array}$ \\
\hline vocalise [1376] & $\begin{array}{l}\text { - blowing raspberries } \\
\text { - reaching out hand into the direction of } \\
\text { - she tool } \\
\text { - shaking wrist while reaching out }\end{array}$ & $\begin{array}{l}\text { level 4: soliciting } \\
\text { level 4: soliciting }\end{array}$ \\
\hline Response of social tools & Actor: social tools & Social tool use levels \\
\hline escape [41] & $\begin{array}{l}\text { - going to the direction of the buttons } \\
\text { without pushing } \\
\text { - running away from the buttons and the } \\
\text { - pressing the buttons to release juice at } \\
\text { the fountain }\end{array}$ & $\begin{array}{l}\text { level 3: self-controlled } \\
\text { action without being } \\
\text { constrained }\end{array}$ \\
\hline
\end{tabular}




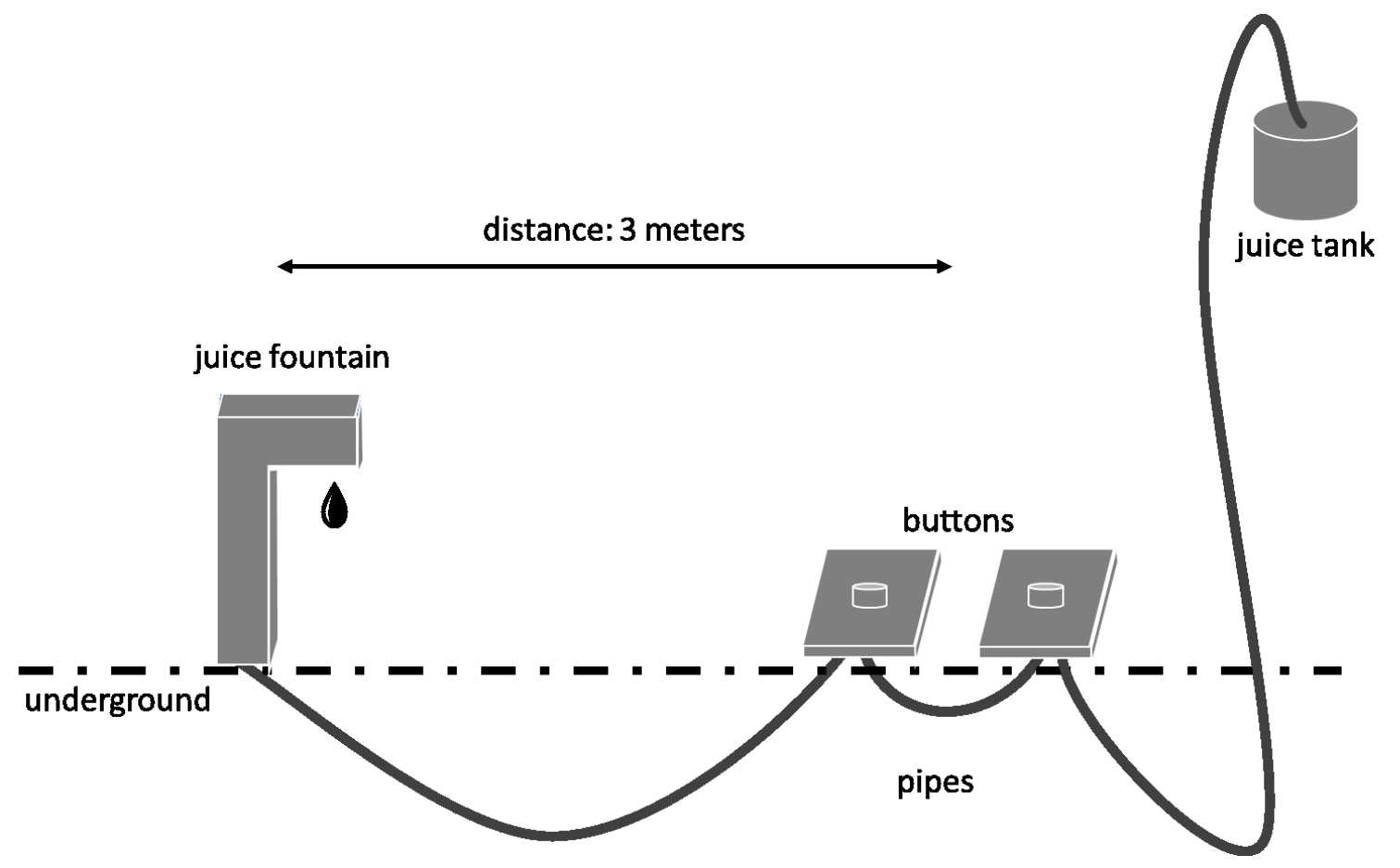

468 Figure 1 . Setting

469 Juice was stored in a juice tank outside the enclosure. By pushing both buttons simultaneously, the

470 juice was delivered via underground pipes to the distant fountain. Because the buttons and the 471 fountain were 3 meters apart, pushers could not drink directly from the fountain. 

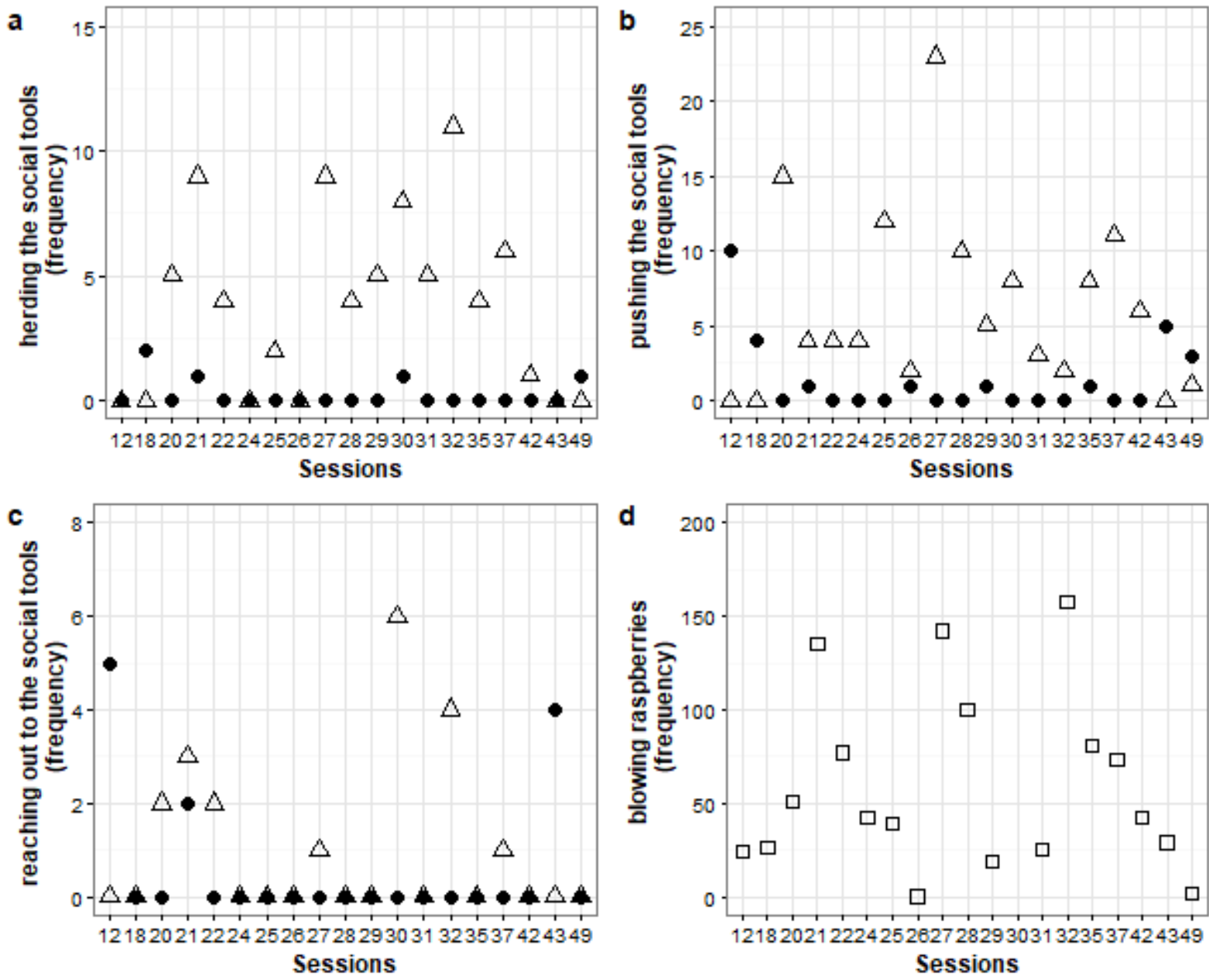

Figure 2. Social tool use behaviour over time and across social tools

474 The social tool user showed 4 different behaviours to encourage his social tools to provide juice to him.

475 First, he retrieved the social tools (panel a), then he pushed the respective tool into the direction of

476 the buttons (panel b), which was sometimes followed by reaching out his hand (panel c). He blew

477 raspberries throughout the sequences (panel d). Whereas blowing raspberries was not focused on

478 specific individuals, the first three behaviours were clearly directed to either one of the social tools

479 (depicted in squares, panels d). Social tool use was directed more often to Kenny (open triangles,

480 panels a-c) than to Jewel (filled points, panels a-c) and none of the behaviours varied over time (panels 481 a-d). 


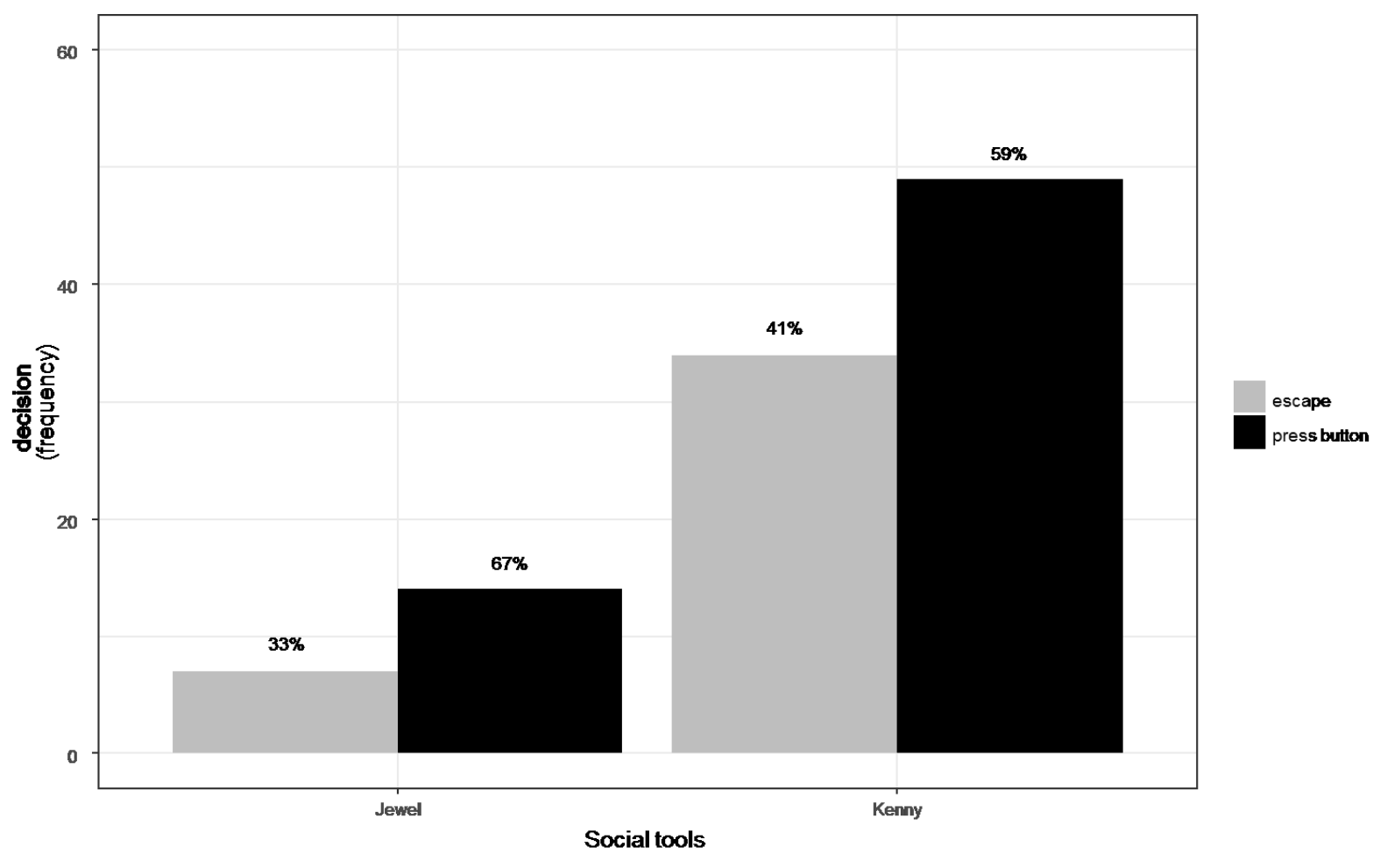

483 Figure 3 . Response of the social tools to harassment

484 The social tools could either press the buttons (black bars) or escape (grey bars). Overall Kenny was 485 used more often than Jewel. The ratio between escaping and pressing tended to be more biased 486 towards giving in to pressing the buttons by Jewel, but this was non-significant. 